\title{
HGH Gene
}

National Cancer Institute

\section{Source}

National Cancer Institute. hGH Gene. NCI Thesaurus. Code C20223.

HGH Genes (Somatotropin/Prolactin Family) share a high degree of sequence identity and encode alternatively spliced diverse isoforms of Growth Hormone, a small secreted peptide hormone that affects gene expression, metabolism, and growth control. Due to alternative splicing, differential posttranslational modifications, optional binding to GHBP or alpha2-macroglobulin, and potential proteolytic processing, circulating GH shows great heterogeneity as a disulfide-linked or non-covalently associated monomer, dimer, trimer, tetramer, or pentamer in homopolymeric and heteropolymeric combinations. GH stimulates the liver and other tissues to secrete IGF-1. GH stimulates amino acid uptake and protein synthesis in muscle and other tissues and stimulates differentiation and proliferation of myoblasts. GH also stimulates mitosis, cell growth, and differentiation of other cell types. $(\mathrm{NCl})$ 